\title{
Planejamento experimental em milho ${ }^{1}$
}

\author{
Experimental design in corn
}

\begin{abstract}
Alberto Cargnelutti Filho ${ }^{2 *}$ e José Paulo Guadagnin ${ }^{3}$
Resumo - É importante dimensionar o número de repetições para avaliar caracteres de cultivares de milho com precisão desejada. O objetivo deste trabalho foi determinar o número de medições (repetições) necessárias para avaliar caracteres de cultivares de milho (Zea mays L.). Foram usados os dados coletados em 16 experimentos de competição de cultivares, realizados no Estado do Rio Grande do Sul, nos anos agrícolas 2002/2003, 2003/2004 e 2004/2005. Em cada experimento, foi utilizado um delineamento de blocos ao acaso, com três blocos ou repetições. Foram medidos os caracteres número de dias da semeadura até $50 \%$ do florescimento masculino, alturas de planta e de espiga na colheita e número de espigas na colheita. Foram verificados os pressupostos do modelo matemático, realizada a análise de variância, estimado o coeficiente de repetibilidade e calculado o número de repetições. Experimentos com quatro repetições são suficientes para avaliar os caracteres número de dias da semeadura até $50 \%$ do florescimento masculino, alturas de planta e de espiga na colheita e número de espigas na colheita, de cultivares de milho, com, respectivamente, 88,$7 ; 75,1 ; 74,5$ e $69,4 \%$ de precisão.
\end{abstract}

Palavras-chave - Zea mays L. Número de repetições. Precisão experimental.

\begin{abstract}
It is important to know the number of replications to evaluate characters of corn cultivars with desired accuracy. The objective of this work was to determine how many evaluations (replications) necessary to evaluate characters of corn (Zea mays L.) cultivars. Data were collected from 16 cultivar competition trials of corn, carried out in the Rio Grande do Sul State, Brazil, in the crop years of 2002/2003, 2003/2004 and 2004/2005. In each experiment, it was used a randomized blocks design with three blocks or replications. The following characters were measured: number of days from sowing to $50 \%$ flowering male, plant and ear heights at harvest and the number of ears at harvest. Assumptions of the mathematical model were examined, analysis of variance was performed, the repeatability coefficient was estimated and the number of repetitions was calculated. Experiments with four replications are adequate to evaluate the characters number of days from sowing to $50 \%$ flowering male, plant height, ear height and the number of ears, with respectively $88.7 ; 75.1 ; 74.5$ and $69.4 \%$ of accuracy.
\end{abstract}

Key words - Zea mays L. Number of replications. Experimental precision.

\footnotetext{
* Autor para correspondência

${ }^{1}$ Recebido para publicação em 24/01/2011; aprovado em 01/06/2011

Pesquisa desenvolvida no Estado do Rio Grande do Sul

${ }^{2}$ Departamento de Fitotecnia, Centro de Ciências Rurais, Universidade Federal de Santa Maria, Campus Universitário, Camobi, Santa Maria-RS, Brasil, 97.105-900, cargnelutti@pq.cnpq.br

${ }^{3}$ Fundação Estadual de Pesquisa Agropecuária (FEPAGRO), Rua Gonçalves Dias, 570, Bairro Menino Deus, Porto Alegre-RS, Brasil, 90.130-060, jpguadagnin@ibest.com.br
} 


\section{Introdução}

Nas etapas finais de um programa de melhoramento genético de milho (Zea mays L.), o desempenho agronômico de cultivares é avaliado em ensaios de competição, realizados em distintos ambientes. Nesses experimentos, além da produtividade de grãos, outros caracteres têm sido pesquisados. É importante que esses experimentos tenham uma precisão experimental adequada para que as inferências, em relação aos caracteres em avaliação, tenham confiabilidade.

No planejamento experimental, a utilização do número adequado de repetições é uma técnica importante a ser considerada, e esse número tem sido um questionamento comum entre os pesquisadores. $\mathrm{Na}$ cultura do milho, o número adequado de repetições tem sido investigado por Oliveira et al. (2005), Velini et al. (2006), Catapatti et al. (2008) e Cargnelutti Filho et al. (2010). De maneira geral, esses trabalhos destacaram a melhoria da precisão por meio de um planejamento experimental adequado. Outras técnicas experimentais em milho, abordando aspectos relacionados ao tamanho ótimo de parcela (ALVES; SERAPHIN, 2004; MARTIN et al., 2005a; SOUZA SOBRINHO et al., 2004; STORCK et al., 2006b), às bordaduras das fileiras (CARGNELUTTI FILHO et al., 2003; CONCEIÇÃO; SILVA; MACHADO, 1993), ao tamanho de amostra (MARTIN et al., 2005b; SILVA et al., 1993; STORCK et al., 2007) e a correção da produtividade de grãos de parcelas experimentais (SCHIMILDT et al., 2006), foram consideradas eficientes na melhoria da precisão experimental.

Estimativas de coeficiente de repetibilidade, por meio da análise de variância (CRUZ, 2006), têm sido utilizadas no dimensionamento do número de repetições, para avaliar a produtividade de grãos, em nove ensaios de cultivares de feijão (CARGNELUTTI FILHO; RIBEIRO; STORCK; 2009), em 216 ensaios de genótipos de soja (STORCK et al., 2009) e em 286 ensaios de cultivares de milho (CARGNELUTTI FILHO; STORCK; GUADAGNIN, 2010). A abordagem adotada nesses trabalhos permitiu concluir que: 1) ensaios com quatro repetições possibilitam a identificação de cultivares superiores de feijão em relação à produtividade de grãos, com $85 \%$ de exatidão no prognóstico de seu valor real (CARGNELUTTI FILHO; RIBEIRO; STORCK; 2009); 2) ensaios com quatro repetições e analisados com o método de Papadakis possibilitam a identificação de genótipos superiores de soja em relação à produtividade de grãos, com $80 \%$ de precisão (STORCK et al., 2009); e 3) ensaios com três e quatro repetições identificam cultivares superiores de milho, em relação à produtividade de grãos, com, respectivamente, 72,40 e $81 \%$ de exatidão no prognóstico de seu valor real (CARGNELUTTI FILHO; STORCK; GUADAGNIN, 2010).

O dimensionamento do número de repetições, a partir das estimativas de coeficiente de repetibilidade, obtidas por meio da análise de variância, é uma técnica de análise que minimiza custos e aproveita os dados experimentais existentes para redefinição ou manutenção de planejamentos experimentais. No entanto, para a cultura do milho, foi encontrado, na literatura, estudo sobre o emprego da análise de repetibilidade para a estimativa do número de repetições, somente para a produtividade de grãos.

O objetivo deste trabalho foi determinar o número de medições (repetições) necessárias para avaliar os caracteres número de dias da semeadura até $50 \%$ do florescimento masculino, alturas de planta e de espiga na colheita e número de espigas na colheita, de cultivares de milho.

\section{Material e métodos}

Foram usados os dados do número de dias da semeadura até $50 \%$ do florescimento masculino (DF), das alturas de planta (AP) e de espiga (AE) na colheita e do número de espigas na colheita (NE), coletados em 16 experimentos de competição de cultivares de milho. Os experimentos foram realizados no Estado do Rio Grande do Sul e classificados conforme a categoria (estadual e indicado), o ciclo (precoce e superprecoce) e o ano agrícola $(2002 / 2003,2003 / 2004$ e 2004/2005) (TAB. 1). Em todos os experimentos, as unidades experimentais, que continham as cultivares, foram casualizadas conforme o delineamento blocos ao acaso com três repetições, sendo as unidades experimentais constituídas de duas fileiras com $5 \mathrm{~m}$ de comprimento, com espaçamento entre 0,7 e $0,9 \mathrm{~m}$.

Em cada um dos 16 experimentos, os dados dos quatro caracteres (DF, AP, AE e NE), seguiram um modelo estatístico de delineamento em blocos ao acaso dado por: $Y_{i j}=\mu+\tau_{i}+\beta_{j}+\varepsilon_{i j}$, no qual $Y_{i j}$ é o valor observado da variável resposta na parcela $i j, \mu$ é a média geral, $\tau_{i}$ é o efeito da cultivar $(\mathrm{i}=1,2, \ldots, \mathrm{I}), \beta_{j}$ é o efeito do bloco $(\mathrm{j}=1,2,3)$ e $\varepsilon_{i j}$ é o efeito do erro experimental suposto normal e independentemente distribuído com média 0 e variância comum $\sigma^{2}$ (STORCK et al., 2006a). Os testes de Kolmogorov Smirnov, Levene e aditividade de Tukey foram utilizados para verificar o atendimento, respectivamente, das pressuposições de normalidade dos erros, homogeneidade de variâncias e aditividade do modelo matemático. Com base nos resultados da análise de variância, foram obtidas as estimativas do quadrado médio 
Tabela 1 - Relação dos 16 experimentos de competição de cultivares de milho conduzidos em diferentes locais do Estado do Rio Grande do Sul, com respectiva classificação conforme a categoria, o ciclo e o ano agrícola, e o número de cultivares avaliadas

\begin{tabular}{cccccc}
\hline Experimento & Local & Categoria ${ }^{(1)}$ & Ciclo & Ano agrícola & Número de cultivares \\
\hline 1 & Passo Fundo & Estadual & Precoce & $2003 / 2004$ & 40 \\
2 & Capão do Leão & Estadual & Precoce & $2004 / 2005$ & 32 \\
3 & Carazinho & Estadual & Precoce & $2004 / 2005$ & 32 \\
4 & Cruz Alta & Estadual & Precoce & $2004 / 2005$ & 32 \\
5 & Passo Fundo & Estadual & Superprecoce & $2002 / 2003$ & 11 \\
6 & Passo Fundo & Estadual & Superprecoce & $2003 / 2004$ & 9 \\
7 & Capão do Leão & Estadual & Superprecoce & $2004 / 2005$ & 17 \\
8 & Carazinho & Estadual & Superprecoce & $2004 / 2005$ & 17 \\
9 & Cruz Alta & Estadual & Superprecoce & $2004 / 2005$ & 17 \\
10 & Santa Maria & Indicado & Precoce & $2002 / 2003$ & 27 \\
11 & Passo Fundo & Indicado & Precoce & $2003 / 2004$ & 26 \\
12 & Santa Maria & Indicado & Precoce & $2004 / 2005$ & 30 \\
13 & Passo Fundo & Indicado & Superprecoce & $2002 / 2003$ & 18 \\
14 & Passo Fundo & Indicado & Superprecoce & $2003 / 2004$ & 16 \\
15 & Pelotas & Indicado & Superprecoce & $2003 / 2004$ & 16 \\
16 & Cruz Alta & Indicado & Superprecoce & $2004 / 2005$ & 12 \\
\hline
\end{tabular}

(1) $\mathrm{Na}$ categoria dos experimentos estaduais, as cultivares avaliadas foram aquelas ainda não indicadas aos produtores, e as cultivares indicadas (já recomendadas aos produtores) foram estudadas na categoria dos experimentos indicados

de bloco $\left(\mathrm{QM}_{\mathrm{B}}\right)$, do quadrado médio de cultivar $\left(\mathrm{QM}_{\mathrm{C}}\right)$, do quadrado médio do erro $\left(\mathrm{QM}_{\mathrm{E}}\right)$ e do valor do teste $\mathrm{F}$ para cultivar $\left(\mathrm{Fc}=\mathrm{QM}_{\mathrm{C}} / \mathrm{QM} \mathrm{E}_{\mathrm{E}}\right)$. Logo após, foi estimada a acurácia seletiva (AS) (RESENDE; DUARTE, 2007), por meio da expressão $\mathrm{AS}=(1-(1 / \mathrm{Fc}))^{0,5}$. Posteriormente, com base em AS, foi avaliada a precisão experimental de acordo com os limites de classes estabelecidos em Cargnelutti Filho e Storck (2009).

Foram consideradas as avaliações em cada bloco como medições realizadas no mesmo indivíduo (cultivar) e foi estimado o coeficiente de repetibilidade (r), em cada caractere e experimento, por meio da análise de variância. Nesse estudo, o coeficiente de repetibilidade é o coeficiente de correlação intraclasse para cultivares e é estimado por meio da expressão $r=\left[\left(\mathrm{QM}_{\mathrm{C}}-\mathrm{QM}_{\mathrm{E}}\right) / \mathrm{J}\right] /\left[\left(\mathrm{QM}_{\mathrm{C}}-\mathrm{QM}_{\mathrm{E}}\right) / \mathrm{J}\right.$ $+\mathrm{QM}_{\mathrm{E}}$ ], em que J é o número de repetições (CRUZ, 2006; CRUZ; REGAZZI, 1997).

O número mínimo de repetições $(\mathrm{J})$ necessário para predizer o valor real dos indivíduos (cultivares), com base nos coeficientes de determinação genotípico $\left(\mathrm{R}^{2}\right)$ préestabelecidos $(0,80 ; 0,85$ e 0,90$)$, foi calculado por meio da expressão $\mathrm{J}=\left[\mathrm{R}^{2}(1-\mathrm{r})\right] /\left[\left(1-\mathrm{R}^{2}\right) \mathrm{r}\right](\mathrm{CRUZ}$; REGAZZI, 1997). O coeficiente de determinação genotípico $\left(R^{2}\right)$, que representa a certeza da predição do valor real das cultivares selecionadas, com base em $\mathrm{J}$ medições realizadas, foi obtido pela expressão $\mathrm{R}^{2}=[\mathrm{Jr}] /[1+\mathrm{r}(\mathrm{J}-1)]$, em que $\mathrm{J}$ é o número de medições realizadas $(\mathrm{J}=3$ blocos neste estudo) e r é o coeficiente de repetibilidade (CRUZ, 2006). Ainda, com base na média do coeficiente de repetibilidade (r) entre os 16 experimentos, em cada um dos caracteres, foi calculado o coeficiente de determinação genotípico $\left(\mathrm{R}^{2}\right)$ em função de diferentes números de repetições (J variando de 0 até 50). Embora experimentos com zero repetição não tenham sentido prático e com 50 repetições serem, praticamente, inviáveis de serem realizados, optouse por esses limites para demonstrar graficamente o comportamento da relação entre $\mathrm{R}^{2}$ e $\mathrm{J}$, com base em um valor fixo de $\mathrm{r}$ ( $\mathrm{r}=$ média dos 16 experimentos). As análises estatísticas foram realizadas com o auxílio dos softwares GENES (CRUZ, 2006) e Office Excel.

\section{Resultados e discussão}

Nos 64 casos analisados (4 caracteres $\times 16$ experimentos), o valor de $\mathrm{P}$ (nível mínimo de significância) do teste de normalidade (Kolmogorov-Smirnov), oscilou entre 0,0905 e 0,9989 e a média dos 64 valores de $\mathrm{P}$ do teste de normalidade foi 0,637. Em nível de 5\% de significância, valor comumente utilizado, o valor de $\mathrm{P}$ do teste de normalidade, evidenciou que os erros ajustaram-se 
à distribuição normal. Também em $100 \%$ dos casos as variâncias dos erros não foram consideradas heterogêneas $(\mathrm{P}>0,05)$ pelo teste de Levene. Em apenas 3 casos $(4,69 \%)$, o teste de aditividade de Tukey revelou não aditividade no modelo matemático $(\mathrm{P} \leq 0,05)$. Portanto, os percentuais de atendimento desses pressupostos do delineamento em blocos ao acaso indicaram que os testes de hipóteses podem ser aplicados sem restrições de validade (STORCK et al., 2006a). Assim, nas análises estatísticas, utilizaram-se os dados reais.

$\mathrm{O}$ teste $\mathrm{F}$ da análise de variância revelou efeito de bloco significativo $(\mathrm{P} \leq 0,05)$ em 18 casos $(28,13 \%)$, evidenciando blocos heterogêneos e que o uso do delineamento blocos ao acaso foi adequado. Por outro lado, em 46 casos $(71,87 \%)$, os blocos não foram heterogêneos (TAB. 2). Apesar de, na maioria dos casos, pela não significância do efeito de blocos, ser adequado o uso do delineamento inteiramente casualizado, o uso de blocos deve continuar sendo utilizado nessas áreas experimentais, como forma de garantir o controle dessa fonte de heterogeneidade, no caso de sua existência. Percentuais semelhantes a esses foram obtidos em relação à produtividade de grãos, avaliada em 216 ensaios de genótipos de soja (STORCK et al., 2009) e em 286 ensaios de cultivares de milho (CARGNELUTTI FILHO; STORCK; GUADAGNIN, 2010).

Em relação ao número de dias da semeadura até $50 \%$ do florescimento masculino (DF), às alturas de planta (AP) e de espiga (AE) na colheita e ao número de espigas na colheita (NE), houve efeito de cultivar significativo $(\mathrm{P} \leq$ $0,05)$, respectivamente, em 15; 11; 12 e 13 experimentos, o que evidencia a possibilidade de identificação de cultivares superiores. Nos 13 casos (20,31\%) em que não houve efeito significativo de cultivar, a não discriminação das cultivares, por meio do teste $\mathrm{F}$, pode não ser devido a não existência de variabilidade genética e sim, provavelmente, à menor precisão experimental (CARGNELUTTI FILHO; STORCK, 2007, 2009; RESENDE; DUARTE, 2007). Nos 51 casos $(79,69 \%)$ com efeito significativo de cultivares, a média do valor do teste $\mathrm{F}$ para cultivar $(\mathrm{Fc})$, da acurácia seletiva (AS) e dos coeficientes de repetibilidade (r) e de determinação genotípico $\left(\mathrm{R}^{2}\right)$, com base nas três repetições, foi de 7,172;0,870;0,551 e 0,762, respectivamente. Enquanto que, nos experimentos em que não foram detectadas diferenças significativas, as médias de Fc, AS, $\mathrm{r}$ e $\mathrm{R}^{2}$ foram, respectivamente, 1,$557 ; 0,550 ; 0,149$ e 0,324 (TAB. 2; TAB. 3). As estatísticas valor do teste F para cultivar (Fc) e acurácia seletiva (AS), são mais adequadas do que o coeficiente de variação $(\mathrm{CV})$, para a avaliação da precisão experimental em ensaios de competição de cultivares de milho. Os maiores escores das estatísticas valor do teste $\mathrm{F}$ para cultivar $(\mathrm{Fc})$ e acurácia seletiva (AS) estão associados às maiores variabilidades genéticas e menores variâncias residuais, o que indica experimentos mais precisos (CARGNELUTTI FILHO; STORCK, 2007, 2009). Portanto, esses resultados confirmam que a não identificação de diferenças entre as cultivares está associada à menor precisão experimental.

De acordo com limites de classes das estatísticas - valor do teste $\mathrm{F}$ para cultivar $(\mathrm{Fc})$ e acurácia seletiva (AS) - estabelecidos em Cargnelutti Filho e Storck (2009), dos 64 casos avaliados, 22 apresentaram precisão experimental muito alta ( $\mathrm{Fc} \geq 5,2632 ; \mathrm{AS} \geq 0,90), 30 \mathrm{com}$ precisão alta $(1,9608 \leq \mathrm{Fc}<5,2632 ; 0,70 \leq \mathrm{AS}<0,90)$, 7 casos com precisão moderada $(1,3333 \leq \mathrm{Fc}<1,9608$; $0,50 \leq \mathrm{AS}<0,70)$ e 5 casos com precisão baixa ( $\mathrm{Fc}<$ 1,3333; AS < 0,50) (TAB. 2). Esses resultados revelam que há variabilidade das precisões experimentais entre os caracteres e os experimentos. Variabilidade de precisões experimentais, em relação à produtividade de grãos, foi verificada em grupos de experimentos de milho (CARGNELUTTI FILHO; STORCK, 2009; CARGNELUTTI FILHO; STORCK; GUADAGNIN, 2010), de soja (CARGNELUTTI FILHO; STORCK; RIBEIRO, 2009; STORCK et al., 2009, 2010) e de feijão (CARGNELUTTI FILHO; RIBEIRO; STORCK; 2009).

Independentemente do caractere e do experimento, as estatísticas valor do teste $\mathrm{F}$ para cultivar $(\mathrm{Fc})$, acurácia seletiva (AS) e coeficientes de repetibilidade (r) e de determinação genotípico $\left(\mathrm{R}^{2}\right)$, oscilaram, respectivamente, entre os valores mínimos de: 1,102;0,304; 0,033 e 0,092, e máximos de: 35,502; 0,986; 0,920 e 0,972 (TAB. 2; TAB. 3). Essa variabilidade existente entre os experimentos quanto aos valores $\mathrm{Fc}, \mathrm{AS}, \mathrm{r}$ e $\mathrm{R}^{2}$, é particularmente importante nesse estudo, por representar diferentes situações reais e assim possibilitar inferências com aplicações gerais. Experimentos, que até poderiam ser descartados em razão da insuficiência na precisão experimental, de acordo com critérios de Cargnelutti Filho e Storck (2007, 2009) e de Resende e Duarte (2007), foram mantidos. Assim, é possível que as estimativas do número de repetições $(\mathrm{J})$ de determinados caracteres poderiam estar inflacionadas em experimentos com menor precisão experimental. Variabilidade dessas estatísticas e como consequência da estimativa do número de repetições foi obtida em relação à produtividade de grãos, avaliada em: 9 ensaios de cultivares de feijão (CARGNELUTTI FILHO; RIBEIRO; STORCK, 2009), 216 ensaios de genótipos de soja (STORCK et al., 2009) e 286 ensaios de cultivares de milho (CARGNELUTTI FILHO; STORCK; GUADAGNIN, 2010).

A média do coeficiente de repetibilidade (r) entre os 16 experimentos, foi de 0,$663 ; 0,430 ; 0,422$ e 0,361 , respectivamente, para os caracteres número de dias da semeadura até $50 \%$ do florescimento masculino (DF), alturas de planta (AP) e de espiga (AE) na colheita e número 
Tabela 2 - Quadrado médio de bloco $\left(\mathrm{QM}_{\mathrm{B}}\right)$, quadrado médio de cultivar $\left(\mathrm{QM}_{\mathrm{C}}\right)$, valor do teste $\mathrm{F}$ para cultivar ( $\left.\mathrm{Fc}\right)$, coeficiente de variação $(\mathrm{CV})$, acurácia seletiva $(\mathrm{AS})$ e média $(\mathrm{m})$, para quatro caracteres, mensurados em 16 experimentos (E) conduzidos no delineamento blocos ao acaso com três repetições e com diferente número de cultivares (n) de milho

\begin{tabular}{|c|c|c|c|c|c|c|c|c|c|c|c|c|c|}
\hline \multirow[b]{2}{*}{$\mathrm{E}^{(1)}$} & \multirow[b]{2}{*}{$n$} & $\mathrm{QM}_{\mathrm{B}}$ & $\mathrm{QM}_{\mathrm{C}}$ & $\mathrm{Fc}$ & CV (\%) & AS & $\mathrm{m}$ & $\mathrm{QM}_{\mathrm{B}}$ & $\mathrm{QM}_{\mathrm{C}}$ & $\mathrm{Fc}$ & $\mathrm{V}(0$ & $\mathrm{AS}$ & $\mathrm{m}$ \\
\hline & & \multicolumn{6}{|c|}{$\begin{array}{l}\text {----------Número de dias da semeadura até } 50 \% \text { do----------- } \\
\text { florescimento masculino }\end{array}$} & \multicolumn{6}{|c|}{-------Altura de planta nacolheita $(\mathrm{cm})$----- } \\
\hline 1 & 40 & $8,13^{\mathrm{ns}}$ & $19,97 *$ & 2,911 & 3,02 & 0,810 & 86,76 & $1129,38^{*}$ & $411,32 *$ & 3,503 & 4,62 & 0,845 & 234,63 \\
\hline 2 & 32 & $13,76^{\mathrm{ns}}$ & 42,69 & 4,270 & 4,84 & 0,875 & 65,39 & $474,70^{\text {ns }}$ & $735,65^{*}$ & 3,571 & 8,19 & 0,849 & 175,26 \\
\hline 3 & 32 & $1,50^{\mathrm{ns}}$ & $42,96^{*}$ & 10,446 & 2,52 & 0,951 & 80,53 & $551,04^{\mathrm{ns}}$ & $330,88^{\text {ns }}$ & 1,633 & 8,28 & 0,623 & 171,98 \\
\hline 4 & 32 & $12,01^{\mathrm{ns}}$ & $28,56^{*}$ & 3,970 & 3,11 & 0,865 & 86,14 & $664,64 *$ & $257,64 *$ & 4,296 & 3,93 & 0,876 & 196,95 \\
\hline 5 & 11 & $2,82^{\mathrm{ns}}$ & $30,79 *$ & 16,628 & 1,76 & 0,969 & 77,27 & $182,58^{\mathrm{ns}}$ & $508,79 *$ & 6,853 & 4,29 & 0,924 & 201,06 \\
\hline 6 & 9 & $0,33^{\mathrm{ns}}$ & $17,75^{*}$ & 28,400 & 0,97 & 0,982 & 81,22 & $136,11^{\mathrm{ns}}$ & $920,83^{*}$ & 8,527 & 4,47 & 0,940 & 232,22 \\
\hline 7 & 17 & $13,55^{*}$ & $53,91^{*}$ & 30,320 & 2,13 & 0,983 & 62,55 & $490,65^{\text {ns }}$ & $348,54^{\mathrm{ns}}$ & 1,862 & 8,32 & 0,680 & 164,47 \\
\hline 8 & 17 & $1,24^{\mathrm{ns}}$ & $17,57^{*}$ & 4,705 & 2,54 & 0,887 & 76,24 & $1278,43^{*}$ & $272,79^{\text {ns }}$ & 1,624 & 7,77 & 0,620 & 166,86 \\
\hline 9 & 17 & $8,49^{*}$ & $3,80^{*}$ & 2,131 & 1,59 & 0,728 & 84,16 & $670,81^{*}$ & $113,78^{\text {ns }}$ & 1,179 & 5,30 & 0,390 & 185,33 \\
\hline 10 & 27 & $9,42^{*}$ & $25,29 *$ & 14,425 & 1,76 & 0,965 & 75,14 & $49,37^{\mathrm{ns}}$ & $713,01^{*}$ & 7,698 & 4,30 & 0,933 & 224,07 \\
\hline 11 & 26 & $2,47^{\mathrm{ns}}$ & $17,16^{*}$ & 10,671 & 1,50 & 0,952 & 84,37 & $657,69^{*}$ & $639,96^{*}$ & 6,293 & 4,19 & 0,917 & 240,58 \\
\hline 12 & 30 & $1,03^{\mathrm{ns}}$ & $5,26^{*}$ & 7,269 & 1,16 & 0,929 & 73,53 & $424,63^{*}$ & $621,88^{*}$ & 5,945 & 4,57 & 0,912 & 223,80 \\
\hline 13 & 18 & $1,13^{\mathrm{ns}}$ & $28,27^{*}$ & 35,502 & 1,21 & 0,986 & 73,96 & $23,17^{\mathrm{ns}}$ & $250,91^{*}$ & 3,676 & 4,05 & 0,853 & 204,06 \\
\hline 14 & 16 & $0,40^{\mathrm{ns}}$ & $22,69 *$ & 13,647 & 1,57 & 0,963 & 81,98 & $503,65^{*}$ & $433,30 *$ & 3,473 & 5,06 & 0,844 & 220,73 \\
\hline 15 & 16 & $0,15^{\mathrm{ns}}$ & $21,21^{*}$ & 14,127 & 1,96 & 0,964 & 62,40 & $76,56^{\mathrm{ns}}$ & $422,47 *$ & 2,571 & 5,69 & 0,782 & 225,31 \\
\hline \multirow[t]{2}{*}{16} & 12 & $2,69^{\mathrm{ns}}$ & $2,88^{\mathrm{ns}}$ & 1,584 & 1,60 & 0,607 & 84,03 & $13,97^{\mathrm{ns}}$ & $162,03^{\text {ns }}$ & 1,867 & 4,97 & 0,681 & 187,45 \\
\hline & & \multicolumn{6}{|c|}{-----------------Altura de espiga na colheita $(\mathrm{cm})$---------------- } & \multicolumn{6}{|c|}{--Número de espigas na colheita (milhares de espigas ha"-1)-- } \\
\hline 1 & 40 & $98,96^{\mathrm{ns}}$ & $277,01 *$ & 3,671 & 680 & 0,853 & 127,83 & 38 , & * & 2,5 & 1132 & 0,782 & 49,77 \\
\hline 2 & 32 & 568,95 & 252,68 & 3, & 11,17 & 0,822 & 04 & $339,09^{*}$ & $139,29 *$ & 3171 & 1440 & 0,827 & 46,03 \\
\hline 3 & 32 & 101,04 & 7258 & 1,145 & 1 & 0,356 & 8708 & $020^{\mathrm{ns}}$ & $117,94 *$ & 3,007 & 12,17 & 7 & 51,45 \\
\hline 4 & 32 & 277,89 & 203,85 & 2,350 & 762 & 0,758 & 122,05 & $36,08^{\mathrm{ns}}$ & $91,86^{*}$ & 4,087 & 13,44 & 0,869 & 35,27 \\
\hline 5 & 11 & 97,73 & 172,4 & 2 & 8 & 0,7 & 10 & 93 & 96 & 9 , & 5 , & 0 & 58,26 \\
\hline 6 & 9 & $17,59^{\text {ns }}$ & 1082,18 & 13,87 & 0 & 0,963 & 128,52 & 0,0 & 22 & 1,1 & 9, & 2 & 56,99 \\
\hline 7 & 17 & 355,84 & 261,95 & 3,88 & 11,18 & 0,862 & 73,43 & 61,2 & $131,20^{*}$ & 1,9 & 17,58 & 0,703 & 46,36 \\
\hline 8 & 17 & $13,73^{\mathrm{ns}}$ & 122,79 & 1,265 & 12,35 & 0,458 & 79,80 & 5,55 & 49,8 & 2,1 & 8,83 & 0,731 & 54,58 \\
\hline 9 & 17 & $445,26^{*}$ & 225,55 & 2,276 & 8,88 & 0,749 & 112,06 & 442,1 & & 7,4 & 9,52 & 0,930 & 37,30 \\
\hline 10 & 27 & $1,23^{\mathrm{ns}}$ & 700,87 & 8,813 & 6,87 & 0,942 & 129,77 & $23,84^{\text {ns }}$ & $82,79 *$ & 2,840 & 11,84 & 0,805 & 45,60 \\
\hline 11 & 26 & $29,17^{\mathrm{ns}}$ & $479,38^{*}$ & 6,107 & 6,53 & 0,914 & 135,64 & $0,06^{\mathrm{ns}}$ & $22,07 *$ & 2,366 & 5,93 & 0,760 & 51,54 \\
\hline 12 & 30 & $45,64^{\mathrm{ns}}$ & $297,68^{*}$ & 6,396 & 5,02 & 0,919 & 135,91 & $0,49^{\mathrm{n}}$ & $67,63^{*}$ & 2,407 & 9,88 & 0,765 & 53,65 \\
\hline 13 & 18 & $8,80^{\mathrm{ns}}$ & $141,39^{*}$ & 2,385 & 7,16 & 0,762 & 107,59 & $2,81^{\mathrm{ns}}$ & $31,63^{\mathrm{ns}}$ & 1,728 & 7,25 & 0,649 & 58,98 \\
\hline 14 & 16 & $131,25^{*}$ & $204,41^{*}$ & 5,554 & 5,10 & 0,906 & 119,06 & $21,22^{\mathrm{ns}}$ & $139,84 *$ & 3,921 & 11,31 & 0,863 & 52,79 \\
\hline 15 & 16 & $114,06^{\mathrm{ns}}$ & $412,08^{*}$ & 3,036 & 9,01 & 0,819 & 129,38 & $7,06^{\mathrm{ns}}$ & $89,71^{\text {ns }}$ & 1,102 & 18,30 & 0,304 & 49,32 \\
\hline 16 & 12 & $104,24^{\mathrm{ns}}$ & $165,73^{\mathrm{ns}}$ & 1,836 & 8,31 & 0,675 & 114,40 & $42,23^{\mathrm{ns}}$ & $58,22 *$ & 2,840 & 11,46 & 0,805 & 39,51 \\
\hline
\end{tabular}

(1) Experimentos definidos na Tabela 1; * Efeito significativo, pelo teste $\mathrm{F}$, em nível de 5\% de significância. ${ }^{\text {ns }}$ Não significativo 
Tabela 3 - Estimativa dos coeficientes de repetibilidade (r), dos coeficientes de determinação genotípico $\left(\mathrm{R}^{2}\right)$ e do número de medições (repetições) $(\mathrm{J}){ }^{(1)}$, associado a diferentes $\mathrm{R}^{2}$ de quatro caracteres de cultivares de milho, avaliadas em 16 experimentos

\begin{tabular}{|c|c|c|c|c|c|c|c|c|c|c|}
\hline \multirow{2}{*}{$\mathrm{E}^{(2)}$} & $\mathrm{r}$ & $\mathrm{R}^{2}$ & $\begin{array}{c}\mathrm{J} \\
\left(\mathrm{R}^{2}=0,80\right)\end{array}$ & $\begin{array}{c}\mathrm{J} \\
\left(\mathrm{R}^{2}=0,85\right)\end{array}$ & $\begin{array}{c}\mathrm{J} \\
\left(\mathrm{R}^{2}=0,90\right)\end{array}$ & $\mathrm{r}$ & $\mathrm{R}^{2}$ & $\begin{array}{c}\mathrm{J} \\
\left(\mathrm{R}^{2}=0,80\right)\end{array}$ & $\begin{array}{c}\mathrm{J} \\
\left(\mathrm{R}^{2}=0,85\right)\end{array}$ & $\begin{array}{c}\mathrm{J} \\
\left(\mathrm{R}^{2}=0,90\right)\end{array}$ \\
\hline & \multicolumn{5}{|c|}{$\begin{array}{l}\text {--Número de dias da semeadura até } 50 \% \text { do florescimento-- } \\
\text { masculino }\end{array}$} & \multicolumn{5}{|c|}{------------Altura de planta na colheita (cm)------------ } \\
\hline 1 & 0,389 & 0,656 & 6,3 & 8,9 & 14,1 & 0,455 & 0,715 & 4,8 & 6,8 & 10,8 \\
\hline 2 & 0,522 & 0,766 & 3,7 & 5,2 & 8,3 & 0,462 & 0,720 & 4,7 & 6,6 & 10,5 \\
\hline 3 & 0,759 & 0,904 & 1,3 & 1,8 & 2,9 & 0,174 & 0,388 & 19,0 & 26,9 & 42,7 \\
\hline 4 & 0,497 & 0,748 & 4,0 & 5,7 & 9,1 & 0,524 & 0,767 & 3,6 & 5,2 & 8,2 \\
\hline 5 & 0,839 & 0,940 & 0,8 & 1,1 & 1,7 & 0,661 & 0,854 & 2,1 & 2,9 & 4,6 \\
\hline 6 & 0,901 & 0,965 & 0,4 & 0,6 & 1,0 & 0,715 & 0,883 & 1,6 & 2,3 & 3,6 \\
\hline 7 & 0,907 & 0,967 & 0,4 & 0,6 & 0,9 & 0,223 & 0,463 & 13,9 & 19,7 & 31,3 \\
\hline 8 & 0,553 & 0,787 & 3,2 & 4,6 & 7,3 & 0,172 & 0,384 & 19,2 & 27,3 & 43,3 \\
\hline 9 & 0,274 & 0,531 & 10,6 & 15,0 & 23,9 & 0,056 & 0,152 & 67,0 & 94,9 & 150,8 \\
\hline 10 & 0,817 & 0,931 & 0,9 & 1,3 & 2,0 & 0,691 & 0,870 & 1,8 & 2,5 & 4,0 \\
\hline 11 & 0,763 & 0,906 & 1,2 & 1,8 & 2,8 & 0,638 & 0,841 & 2,3 & 3,2 & 5,1 \\
\hline 12 & 0,676 & 0,862 & 1,9 & 2,7 & 4,3 & 0,622 & 0,832 & 2,4 & 3,4 & 5,5 \\
\hline 13 & 0,920 & 0,972 & 0,3 & 0,5 & 0,8 & 0,471 & 0,728 & 4,5 & 6,4 & 10,1 \\
\hline 14 & 0,808 & 0,927 & 0,9 & 1,3 & 2,1 & 0,452 & 0,712 & 4,9 & 6,9 & 10,9 \\
\hline 15 & 0,814 & 0,929 & 0,9 & 1,3 & 2,1 & 0,344 & 0,611 & 7,6 & 10,8 & 17,2 \\
\hline 16 & 0,163 & 0,369 & 20,5 & 29,1 & 46,2 & 0,224 & 0,464 & 13,8 & 19,6 & 31,1 \\
\hline \multirow[t]{2}{*}{ Média } & 0,663 & 0,855 & 2,0 & 2,9 & 4,6 & 0,430 & 0,694 & 5,3 & 7,5 & 11,9 \\
\hline & \multicolumn{5}{|c|}{--------------Altura de espiga na colheita (cm)------------- } & \multicolumn{5}{|c|}{ Número de espigas na colheita (milhares de espigas ha-1) } \\
\hline 1 & 0,471 & 0,728 & 4,5 & 6,4 & 10,1 & 0,344 & 0,611 & 7,6 & 10,8 & 17,2 \\
\hline 2 & 0,410 & 0,676 & 5,8 & 8,2 & 12,9 & 0,420 & 0,685 & 5,5 & 7,8 & 12,4 \\
\hline 3 & 0,046 & 0,126 & 82,9 & 117,5 & 186,6 & 0,401 & 0,667 & 6,0 & 8,5 & 13,5 \\
\hline 4 & 0,310 & 0,575 & 8,9 & 12,6 & 20,0 & 0,507 & 0,755 & 3,9 & 5,5 & 8,7 \\
\hline 5 & 0,297 & 0,559 & 9,5 & 13,4 & 21,3 & 0,745 & 0,898 & 1,4 & 1,9 & 3,1 \\
\hline 6 & 0,811 & 0,928 & 0,9 & 1,3 & 2,1 & 0,048 & 0,131 & 79,6 & 112,7 & 179,1 \\
\hline 7 & 0,491 & 0,743 & 4,2 & 5,9 & 9,3 & 0,245 & 0,494 & 12,3 & 17,4 & 27,7 \\
\hline 8 & 0,081 & 0,210 & 45,3 & 64,1 & 101,8 & 0,277 & 0,534 & 10,5 & 14,8 & 23,5 \\
\hline 9 & 0,298 & 0,561 & 9,4 & 13,3 & 21,2 & 0,681 & 0,865 & 1,9 & 2,7 & 4,2 \\
\hline 10 & 0,723 & 0,887 & 1,5 & 2,2 & 3,5 & 0,380 & 0,648 & 6,5 & 9,2 & 14,7 \\
\hline 11 & 0,630 & 0,836 & 2,3 & 3,3 & 5,3 & 0,313 & 0,577 & 8,8 & 12,4 & 19,8 \\
\hline 12 & 0,643 & 0,844 & 2,2 & 3,2 & 5,0 & 0,319 & 0,585 & 8,5 & 12,1 & 19,2 \\
\hline 13 & 0,316 & 0,581 & 8,7 & 12,3 & 19,5 & 0,195 & 0,421 & 16,5 & 23,4 & 37,1 \\
\hline 14 & 0,603 & 0,820 & 2,6 & 3,7 & 5,9 & 0,493 & 0,745 & 4,1 & 5,8 & 9,2 \\
\hline 15 & 0,404 & 0,671 & 5,9 & 8,3 & 13,3 & 0,033 & 0,092 & 118,1 & 167,3 & 265,7 \\
\hline 16 & 0,218 & 0,455 & 14,4 & 20,3 & 32,3 & 0,380 & 0,648 & 6,5 & 9,2 & 14,7 \\
\hline Média & 0,422 & 0,687 & 5,5 & 7,8 & 12,3 & 0,361 & 0,629 & 7,1 & 10,0 & 15,9 \\
\hline
\end{tabular}

(1) Estimativa menor que um deve ser interpretada como um; ${ }^{(2)}$ Experimentos definidos na Tabela 1 
de espigas na colheita (NE) (TAB. 3). Experimentos que apresentam menor coeficiente de repetibilidade requerem maior número de repetições para predizer o valor real de determinado caráter e vice-versa. Então, a partir da média do coeficiente de repetibilidade (r) entre os 16 experimentos, pode-se inferir que, para a seleção de cultivares superiores, com uma mesma precisão, há necessidade de um maior número de repetições, em relação aos caracteres NE, AE, AP e DF, nessa ordem.

$\mathrm{O}$ coeficiente de determinação genotípico $\left(\mathrm{R}^{2}\right)$, estimado a partir média do coeficiente de repetibilidade (r) entre os 16 experimentos, foi de 0,$855 ; 0,694 ; 0,687 \mathrm{e}$ 0,629 , respectivamente, para os caracteres número de dias da semeadura até $50 \%$ do florescimento masculino (DF), alturas de planta (AP) e de espiga (AE) na colheita e número de espigas na colheita (NE) (TAB. 3). Portanto, pode-se inferir que três repetições possibilitam detectar diferenças genotípicas com 85,$5 ; 69,4 ; 68,7$ e $62,9 \%$ de certeza na predição do valor real da cultivar, respectivamente, em relação aos caracteres DF, AP, AE e NE.
Fixando $\mathrm{J}=4$ repetições o valor estimado do coeficiente de determinação genotípico $\left(\mathrm{R}^{2}\right)$ a partir da expressão $\mathrm{R}^{2}=[\mathrm{Jr}] /[1+\mathrm{r}(\mathrm{J}-1)]$, para o número de dias da semeadura até $50 \%$ do florescimento masculino (DF) é $\mathrm{R}^{2}=(4 * 0,663) / 1+0,663(4-1)=0,887$ e para os caracteres alturas de planta (AP) e de espiga (AE) na colheita e número de espigas na colheita $(\mathrm{NE})$, os valores são, respectivamente, 0,$751 ; 0,745$ e 0,694 . O acréscimo do coeficiente de determinação genotípico $\left(\mathrm{R}^{2}\right)$ com o aumento do número do número de repetições $(\mathrm{J})$ não ocorre de forma linear (FIG. 1). A partir de um determinado número de repetições, o aumento do coeficiente de determinação genotípico $\left(\mathrm{R}^{2}\right)$ passa a ser negligível, o que reflete em um ganho inexpressivo na predição do valor real da cultivar.

$\mathrm{Na}$ prática, essas informações disponibilizadas possibilitam ao pesquisador planejar seus experimentos mais adequadamente, particularmente quanto ao número de repetições ideal, caso o foco seja inferir sobre algum desses caracteres, com uma precisão desejada. Assim, por exemplo, pode-se inferir que quatro repetições forneceram
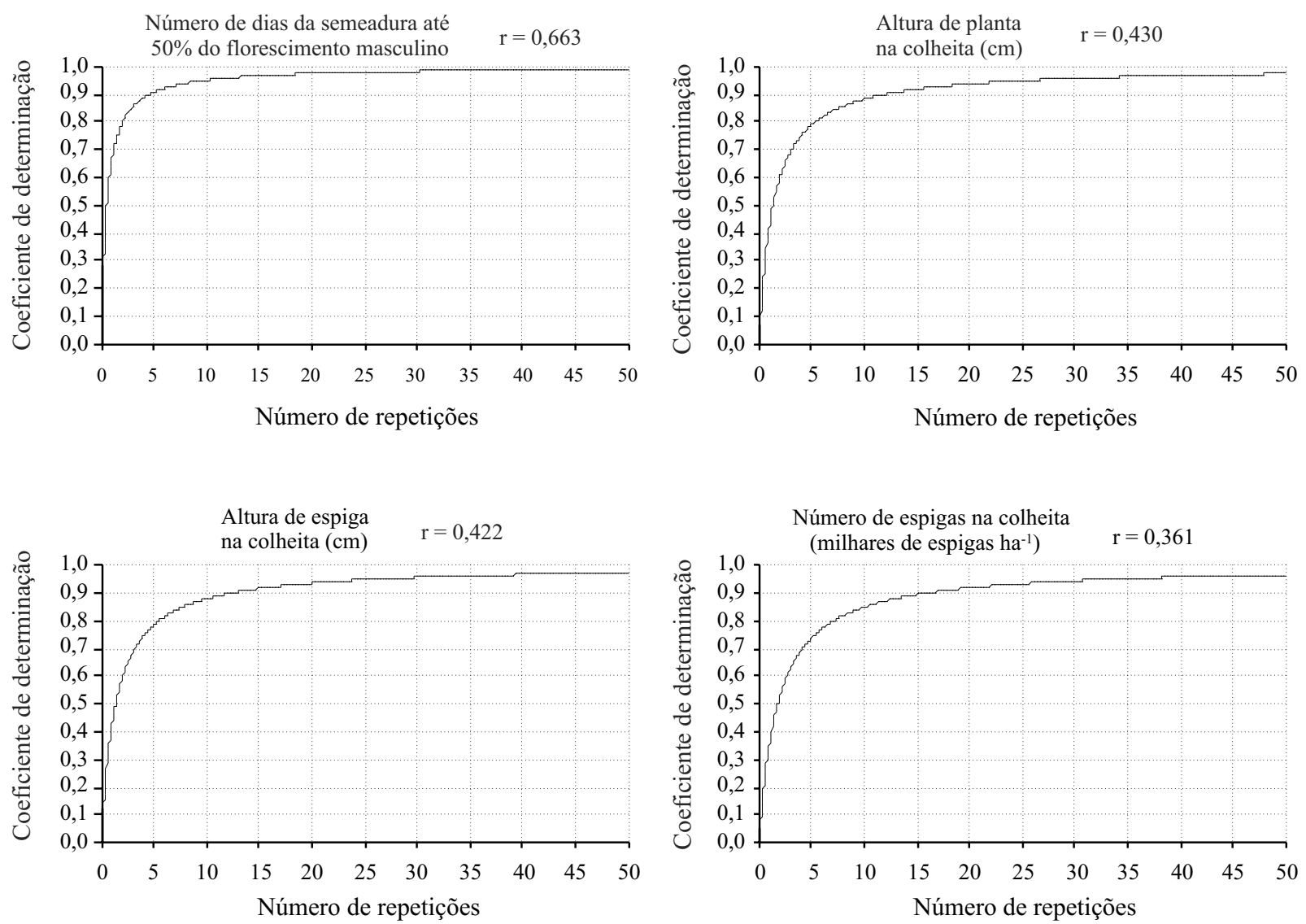

Figura 1 - Estimativa dos coeficientes de determinação genotípico $\left(\mathrm{R}^{2}\right)$, de quatro caracteres, em função do número de medições (repetições) (J), com base no coeficiente de repetibilidade (r) médio de 16 experimentos de avaliação de cultivares de milho 
valores de $\mathrm{R}^{2}$ de $88,7 \%$ para número de dias da semeadura até $50 \%$ do florescimento masculino, de $75,1 \%$ para a altura de planta, 74,5\% para a altura de espiga e de 69,4\% para o número de espigas na colheita. Em relação à produtividade de grãos, o uso de quatro repetições, possibilita a identificação de cultivares superiores de feijão (CARGNELUTTI FILHO; RIBEIRO; STORCK, 2009), de soja (STORCK et al., 2009) e de milho (CARGNELUTTI FILHO; STORCK; GUADAGNIN, 2010), com, respectivamente, $85 ; 80$ e $81 \%$, de exatidão no prognóstico de seu valor real.

\section{Conclusão}

Experimentos com quatro repetições são suficientes para avaliar os caracteres métricos: número de dias da semeadura até $50 \%$ do florescimento masculino, alturas de planta e de espiga na colheita e número de espigas na colheita, de cultivares de milho, com, respectivamente, 88,$7 ; 75,1 ; 74,5$ e $69,4 \%$ de precisão.

\section{Agradecimentos}

Ao Conselho Nacional de Desenvolvimento Científico e Tecnológico (CNPq), pela concessão de bolsa de Produtividade em Pesquisa para Alberto Cargnelutti Filho; à Fundação Estadual de Pesquisa Agropecuária; e aos pesquisadores, pela realização dos experimentos de competição de cultivares de milho no Estado do Rio Grande do Sul.

\section{Referências}

ALVES, S. M. F.; SERAPHIN, J. C. Coeficiente de heterogeneidade do solo e tamanho de parcela. Pesquisa Agropecuária Brasileira, v. 39, n. 02, p. 105-111, 2004.

CARGNELUTTI FILHO, A. et al. A precisão experimental relacionada ao uso de bordaduras nas extremidades das fileiras em ensaios de milho. Ciência Rural, v. 33, n. 04, p. 607-614, 2003

CARGNELUTTI FILHO, A.; STORCK, L. Estatísticas de avaliação da precisão experimental em ensaios de cultivares de milho. Pesquisa Agropecuária Brasileira, v. 42, n. 01, p. 1724, 2007.

CARGNELUTTI FILHO, A.; STORCK, L. Medidas do grau de precisão experimental em ensaios de competição de cultivares de milho. Pesquisa Agropecuária Brasileira, v. 44, n. 02, p. 111-117, 2009.

CARGNELUTTI FILHO, A.; RIBEIRO, N. D.; STORCK, L. Número de repetições para a comparação de cultivares de feijão. Ciência Rural, v. 39, n. 09, p. 2419-2424, 2009.
CARGNELUTTI FILHO, A.; STORCK, L.; RIBEIRO, N. D. Medidas da precisão experimental em ensaios com genótipos de feijão e de soja. Pesquisa Agropecuária Brasileira, v. 44, n. 10, p. 1225-1231, 2009.

CARGNELUTTI FILHO, A.; STORCK, L.; GUADAGNIN, J. P. Número de repetições para a comparação de cultivares de milho. Ciência Rural, v. 40, n. 05, p. 1023-1030, 2010.

CATAPATTI, T. R. et al. Tamanho de amostra e número de repetições para avaliação de caracteres agronômicos em milhopipoca. Ciência e Agrotecnologia, v. 32, n. 03, p. 855-862, 2008.

CONCEIČ̃̃O, M. M.; SILVA, P. S. L.; MACHADO, A. A. Efeitos de bordadura e amostragem em experimento de híbrido de milho. Revista Ciência Agronômica, v. 24, n. 1/2 p. 63-69, 1993.

CRUZ, C. D. Programa Genes: biometria. Viçosa: UFV, 2006. 382 p.

CRUZ, C. D.; REGAZZI, A. J. Modelos biométricos aplicados ao melhoramento genético. 2. ed. Viçosa: UFV, 1997. 390 p.

MARTIN, T. N. et al. Bases genéticas de milho e alterações no plano experimental. Pesquisa Agropecuária Brasileira, v. 40, n. 01, p. 35-40, 2005a.

MARTIN, T. N. et al. Plano amostral em parcelas de milho para avaliação de atributos de espigas. Ciência Rural, v. 35, n. 06, p. $1257-1262,2005 b$

OLIVEIRA, S. J. R. et al. Substituindo o uso de bordaduras laterais por repetições em experimentos com milho. Ciência Rural, v. 35, n. 01, p. 10-15, 2005.

RESENDE, M. D. V.; DUARTE, J. B. Precisão e controle de qualidade em experimentos de avaliação de cultivares. Pesquisa Agropecuária Tropical, v. 37, n. 03, p. 182-194, 2007.

SCHIMILDT, E. R.; KRAUSE, W.; CRUZ, C. D. Melhoria na eficiência dos experimentos de indicação de cultivares de milho. Ciência e Agrotecnologia, v. 30, n. 01, p. 72-80, 2006.

SILVA, P. S. L. et al. Métodos de amostragem e tamanho da amostra para alguns caracteres do milho. Revista Ciência Agronômica, v. 24, n. 1/2, p. 05-10, 1993.

SOUZA SOBRINHO, F. et al. Tamanho de parcela e necessidade de bordadura em avaliações de cultivares de milho para silagem. Revista Brasileira de Milho e Sorgo, v. 03, n. 01, p. 45-51, 2004.

STORCK, L. et al. Experimentação vegetal. 2. ed. Santa Maria: UFSM, 2006a. 198 p.

STORCK, L. et al. Tamanho ótimo de parcela em experimentos com milho relacionado a metodologias. Revista Brasileira de Milho e Sorgo, v. 05, n. 01, p. 48-57, 2006 b.

STORCK, L. et al. Sample size for single, double and triple hybrid corn ear traits. Scientia Agrícola, v. 64, n. 01, p. 30-35, 2007.

STORCK, L. et al. Método de Papadakis e número de repetições em experimentos de soja. Ciência Rural, v. 39, n. 04, p. 977-982, 2009.

STORCK, L. et al. Avaliação da precisão experimental em ensaios de competição de cultivares de soja. Ciência e Agrotecnologia, v. 34, n. 03, p. 572-578, 2010.

VELINI, E. D. et al. Interferência de plantas daninhas na cultura do milho: I - efeito do número de repetições sobre a precisão dos resultados obtidos. Planta Daninha, v. 24, n. 03, p. 435-442, 2006. 